\title{
Excessive cannabis use is associated with earlier age at onset in bipolar disorder
}

\author{
Trine V. Lagerberg $\cdot$ Kjetil Sundet $\cdot$ \\ Sofie R. Aminoff • Akiah O. Berg • Petter A. Ringen • \\ Ole A. Andreassen $\cdot$ Ingrid Melle
}

Received: 30 June 2010/Accepted: 5 January 2011/Published online: 26 January 2011

(C) The Author(s) 2011. This article is published with open access at Springerlink.com

\begin{abstract}
The aim of the study was to investigate which factors are associated with age at onset in bipolar disorder with a specific focus on excessive alcohol and cannabis use, and the sequence of the onsets of excessive substance use and bipolar disorder. We investigated a naturalistic sample of 151 patients with bipolar I and II disorder receiving psychiatric treatment. Whether the presence of excessive substance use prior to bipolar disorder onset or the type of substance used (alcohol or cannabis) was associated with differences in age at onset was investigated using hierarchical and multiple linear regression analyses, adjusting for potential confounders. Patients with excessive alcohol use had a significantly later onset compared with patients with excessive cannabis use. Excessive general substance use prior to bipolar disorder onset was associated with a later onset. However, excessive cannabis use was associated with
\end{abstract}

T. V. Lagerberg · O. A. Andreassen · I. Melle

Psychosis Research Unit, Department of Research and Development, Division of Mental Health and Addiction, Oslo University Hospital, Oslo, Norway

K. Sundet

Department of Psychology, University of Oslo, Oslo, Norway

S. R. Aminoff - A. O. Berg · P. A. Ringen ·

O. A. Andreassen - I. Melle

Department of Psychiatry, Institute of Clinical Medicine, University of Oslo, Oslo, Norway

P. A. Ringen

Department of Psychosis Treatment, Division of Mental Health and Addiction, Oslo University Hospital, Oslo, Norway

T. V. Lagerberg $(\bowtie)$

TOP/Psychosis Research Unit, Oslo University Hospital HF, Ullevål Building 49, P O box 4956, 0424 Oslo, Nydalen, Norway

e-mail: t.v.lagerberg@medisin.uio.no an earlier onset whether it preceded or followed bipolar disorder onset, also after adjusting for possible confounders. Excessive use of alcohol or other substances was not independently associated with age at onset in multivariate analyses. Alcohol use was associated with a later onset compared with cannabis use, suggesting different relationships to the onset of bipolar disorder. Lifetime use of cannabis predicted an earlier onset, independent of the sequence of onsets. This indicates that an early onset may increase the risk of cannabis use and that cannabis use may trigger bipolar disorder in vulnerable individuals.

Keywords Bipolar disorder - Age at onset - Cannabis

\section{Introduction}

The age at onset (AAO) of bipolar disorder (BD) varies from adolescence to mid-adulthood [1], but the reasons for the variation are not fully known. Recent studies find differences in AAO between research sites, with early AAO more often reported from US studies than from European studies [2-4] even though there are exceptions [3, 5, 6]. These variations have been attributed to factors ranging from differences in genetic loading to recruitment biases or methodological discrepancies $[2,6,7]$ such as the definition of illness onset.

However, several other factors have been shown to affect AAO in BD. A family history of affective disorder has been associated with an early onset [8-10]. Most studies find a similar AAO for men and women [11], while some report earlier onsets in females $[12,13]$ and others earlier onsets in men with BD I [3]. The subtypes of BD (BD I and II) appear to have a similar AAO [14]; however, earlier onsets in either BD I or II were also recently 
reported [3, 7]. In addition, experiences of childhood trauma were associated with an earlier onset $[15,16]$.

The relationship between substance abuse and AAO in $\mathrm{BD}$ is poorly understood. The risk for substance abuse (especially of illicit substances) appears to be increased for patients with childhood- and adolescent onset compared with adult onset [13, 17-21], and it has been hypothesized that AAO and substance abuse may share a common genetic etiology [13]. These studies, however, did not differentiate between the types of substances used. Alcohol and cannabis are the two most frequently used substances in BD [22-25]. To the best of our knowledge, the association between type of substance of abuse (alcohol or cannabis) and AAO has not been investigated in previous studies.

Substance abuse may both be a cause and a consequence of early BD onset. One line of research has investigated whether differences in AAO depend on the sequence of the onsets of BD and substance abuse. A later onset has been found among patients with substance abuse that precedes the BD [26-31]. There is also evidence for a less severe clinical course [28, 32-34] and lower rates of family history of affective illness [27] in BD secondary to substance abuse. The later onset, less severe clinical course, and lower rates of family history in patients with BD secondary to substance abuse have been considered markers of a lower constitutional vulnerability and lead to the hypothesis that substance abuse could be necessary for a manifestation of $\mathrm{BD}$ in these individuals [27, 28, 32]. Most studies have focused on either alcohol abuse or substance abuse in general, and the potential to precipitate $\mathrm{BD}$ has been proposed both for alcohol [32, 35], cannabis [29], and even for any substance of abuse [34].

The pharmacological effects of various substances of abuse are often different, and alcohol and cannabis appear to have different effects on the course of an established BD. In a prospective study, cannabis use coincided with or preceded hypomanic or manic symptoms, while alcohol use coincided with or preceded depressive symptoms [36]. Recently, there has been focus on the relationship between $\mathrm{BD}$ and cannabis use in prospective epidemiologic studies. These indicate that cannabis use in the general population is associated with development of manic symptoms [37, 38] and that lifetime cannabis use is associated with a fivefold increase in the risk of developing BD [39].

Only one study has investigated the sequence of the onsets of BD and cannabis use disorders and its relationship to AAO. This indicated that patients with a primary cannabis use disorder had a later onset compared to patients with no cannabis use disorder or a secondary cannabis use disorder [29]. This has not been replicated, and there is a need for further studies that simultaneously evaluate the associations between AAO and excessive alcohol or cannabis use. It is here of particular interest whether the excessive substance use was present before the $\mathrm{BD}$ onset.

In the present study, we investigated a sample of 151 patients with $\mathrm{BD}$. We had the following research questions:

(1) Does AAO differ between patients with excessive alcohol use, excessive cannabis use and patients using neither of these substances?

(2) Do type of excessive substance use (i.e. alcohol or cannabis) and the presence of excessive substance use prior to the $\mathrm{BD}$ onset independently predict $\mathrm{AAO}$ after adjusting for possible confounders? (Table 1).

\section{Methods and materials}

\section{Participants}

A hundred and fifty-one patients with DSM-IV diagnosed bipolar disorder (BD I $n=91$ and BD II $n=60$ ) participated in the study. This patient sample is part of an ongoing study of schizophrenia and BD (the Thematically Organized Psychosis (TOP) study). Patients were recruited consecutively from the psychiatric units (inpatient and outpatient) of the three major hospitals in Oslo from 2003 to 2008. Participants were excluded if they had a history of moderate/severe head injury, neurological disorder, developmental delays, age outside of 18-65 years or if they did not speak a Scandinavian language. All participants gave informed consent, and the project was approved by the Regional Committee for Medical Research Ethics as well as the Norwegian Data Inspectorate. Data on the relationship between AAO, illness severity and time to first treatment for parts of this sample are reported elsewhere [7].

\section{Clinical assessment}

Clinical assessments were carried out by trained clinical psychologists and psychiatrists. Diagnoses were established using the Structured Clinical Interview for DSM-IV (SCID), modules A-E (American Psychiatric Association, 1994). All interviewers were trained based on the training program at UCLA CA, USA, and participated in regular diagnostic consensus meetings. A good inter-rater reliability was achieved with an overall kappa score of 0.77 (95\% CI: 0.60-0.94). AAO was defined as the age when the first SCID-verified affective episode (depressive, hypomanic, manic, or mixed) began. Sociodemographic and clinical variables were cross-checked with participants' medical charts and with information from interviews with close family members if relevant. A family history of depression, BD, schizophrenia, and other psychotic 
Table 1 Summary of previous findings highly relevant for the present study's research questions

\begin{tabular}{|c|c|c|}
\hline Authors, publication & Material/methods & Finding \\
\hline Carlson et al. [17] & $N=43$ (psychotic mania), clinical, 24-month follow-up & \multirow{6}{*}{$\begin{array}{l}\text { Childhood and adolescent BD } \\
\text { onset is associated with } \\
\text { increased risk for substance use } \\
\text { disorders }\end{array}$} \\
\hline Carter et al. [20] & $N=320(229$ BD I, 91 BD II $)$, clinical, cross-sectional & \\
\hline Ernst et al. [18] & $N=56$ (46 BD I, 7 BD II, 3 BD NOS), clinical, cross-sectional & \\
\hline Goldstein et al. [21] & $N=1,411(\mathrm{BD})$, epidemiological, cross-sectional & \\
\hline Lin et al. [13] & $N=717$ (510 BD I, 155 BD II, 52 schiz.aff.), family study, cross-sectional & \\
\hline Perlis et al. [19] & $N=983$ (703 BD I, 239 BD II, 40 BD NOS), clinical, cross-sectional & \\
\hline Feinman et al. [26] & $N=188$ (82 BD I, 42 BD II, 26 cycl., 38 BD NOS), clinical, cross-sectional & \multirow{4}{*}{$\begin{array}{l}\text { Substance use disorders preceding } \\
\text { BD are associated with a later } \\
\text { BD onset }\end{array}$} \\
\hline DelBello et al. [27] & $N=51(\mathrm{BD}$ I), clinical, cross-sectional & \\
\hline Fossey et al. [30] & $N=1,000(710$ BD I, 240 BD II, 40 BD NOS), clinical, cross-sectional & \\
\hline Strakowski et al. [31] & $N=59$ (psychotic mania), clinical, cross-sectional & \\
\hline Strakowski et al. [28] & $N=144$ (BD I), clinical, 5-year follow-up & $\begin{array}{l}\text { Alcohol use disorders preceding } \\
\text { BD are associated with a later } \\
\text { BD onset }\end{array}$ \\
\hline Strakowski et al. [29] & $N=144$ (BD I), clinical, 5-year follow-up & $\begin{array}{l}\text { Cannabis use disorders preceding } \\
\text { BD are associated with a later } \\
\text { BD onset }\end{array}$ \\
\hline Goldstein and Levitt [33] & $N=657$ (BD I), epidemiological, cross-sectional & \multirow{3}{*}{$\begin{array}{l}\text { Alcohol use disorders preceding } \\
\text { BD are associated with a less } \\
\text { severe BD course }\end{array}$} \\
\hline Strakowski et al. [28] & $N=144$ (BD I), clinical, 5-year follow-up & \\
\hline Winokur et al. [32] & $N=231$ (BD I and schizoaffective manic), clinical, 5-year follow-up & \\
\hline Pacchiarotti et al. [34] & $N=289(186$ BD I, 103 BD II), clinical, cross-sectional & $\begin{array}{l}\text { Substance use disorders preceding } \\
\text { BD are associated with a less } \\
\text { severe BD course }\end{array}$ \\
\hline DelBello et al. [27] & $N=51(\mathrm{BD}$ I), clinical, cross-sectional & $\begin{array}{l}\text { Substance use disorders preceding } \\
\text { BD are associated with lower } \\
\text { rates of family history of } \\
\text { affective disorders }\end{array}$ \\
\hline Baethge et al. [36] & $N=166($ BD I), clinical, 4.7-year follow-up & $\begin{array}{l}\text { Cannabis use coincides with or } \\
\text { precedes (hypo)manic } \\
\text { symptoms, while alcohol } \\
\text { coincides with or precedes } \\
\text { depressive symptoms }\end{array}$ \\
\hline Henquet et al. [37] & $N=4,815$ (general population sample), epidemiological, 3-year follow-up & \multirow{2}{*}{$\begin{array}{l}\text { Cannabis use is associated with an } \\
\text { increased risk for developing } \\
\text { manic symptoms }\end{array}$} \\
\hline Tijssen et al. [38] & $\begin{array}{l}N=1,395 \text { (14-17 year olds, population sample), epidemiological, } \\
8 \text {-year follow-up }\end{array}$ & \\
\hline Van Laar et al. [39] & $N=3,881$ (general population sample), epidemiological, 3-year follow-up & $\begin{array}{l}\text { Cannabis use is associated with an } \\
\text { increased risk for developing BD }\end{array}$ \\
\hline
\end{tabular}

disorders among first-degree relatives (i.e. mother, father, brothers, and sisters) was obtained through patient interviews. Patients having a minimum of one first-degree relative with one or more psychiatric disorders were considered to have a family history. A family history of other psychotic disorders than $\mathrm{BD}$ was considered since several recent studies have shown common heritability for BD and schizophrenia [40, 41]. A family history was collected for 148 of the patients. Of these, $62(42 \%)$ had a positive family history of any lifetime affective or psychotic disorder, 41 (27\%) of depression, 20 (14\%) of BD, and $6(4 \%)$ of psychotic disorder. Four patients had a family history of both BD and depression, and one patient had a family history of both BD and psychosis.

\section{Substance use assessments}

Each patient reported lifetime substance use (daily, weekly, monthly, or occasional/no use) for all substances for the following life periods: 11-15 years, 16-20 years, 21-27 years, 28-44 years, 45-60 years, and 60+ years. Patients that either 1) met criteria for a DSM-IV substance use disorder (SUD) or 2) had predominantly daily use of alcohol and/or predominantly weekly use of a non-alcoholic substance through at least one of the life periods above (i.e. for a minimum of 4 years) were considered excessive substance users and included as such in the subsequent analyses. In an earlier study, we have shown that the use patterns and correlates of excessive substance 
use are similar for patients with SUD and patients with excessive substance use according to definition above [42].

Age at onset of excessive substance use was deemed to be either 1) the age when DSM-IV abuse/dependence criteria were first met or 2) the age when the patient started daily use of alcohol or weekly use of (a) non-alcoholic substance(s). Twenty-eight patients (19\%) had excessive use of alcohol, 24 patients $(16 \%)$ had excessive use of cannabis, and 11 patients used both. Patients who used both were similar to the patients who used cannabis only and not to the patients who used alcohol only for all relevant clinical and sociodemographic characteristics and were therefore grouped together with the cannabis-only patients in the bivariate analyses for research question 1. But to further ensure that the differences between the alcohol and the cannabis groups were not due to the characteristics of the patients using both alcohol and cannabis, follow-up analyses were conducted where these patients were excluded. Among the 88 patients with neither excessive alcohol nor cannabis use, three patients had excessive use of other substances, which were excluded from the bivariate analyses.

Sequencing of onsets of BD and excessive substance use

For research question 2, the total sample was subdivided into two groups based on the presence (secondary BD) or absence (primary BD) of excessive substance use prior to the first affective episode. This dichotomous variable is subsequently referred to as the sequencing of onsets. The small group of patients $(n=6)$ whose onsets of the first affective episode and excessive substance use occurred within the same year were categorized as secondary BD. This was done because excessive substance use to a greater degree than BD has a gradual rather than an abrupt onset.
Since all patients in this study eventually were diagnosed with BD, affective episodes associated with substance use in patients with no previous BD episode were used as markers for AAO. Using these criteria, 117 (77\%) patients had primary BD and $34(23 \%)$ had secondary BD. Patients with primary $\mathrm{BD}$ could theoretically develop excessive substance use after the onset of $\mathrm{BD}$, and data showed that 32 patients $(21 \%)$ subsequently did. Sociodemographic and clinical characteristics in the two groups are described in Table 2 .

\section{Statistical analysis}

All analyses were done using the Statistical Package for the Social Sciences (SPSS) version 16.0 (Inc., Chicago, IL, USA). Statistical significance was determined using the 0.05 level and 2-tailed tests of significance. One-way ANOVAs with Tukey's post hoc tests were used to compare the groups on continuous variables. Dichotomous variables were analyzed with chi-square tests with corresponding post hoc analyses performed using chi-squares with a Bonferroni corrected alpha level for the three group comparisons set to 0.017 . Pearson correlations were used to assess bivariate associations between the dependent and the independent variables. A two-way ANOVA was used to investigate the possible interaction effects of type of substance use and sequencing. The contributions of the independent variables were then further explored with multiple regression analyses. Possible confounders of the relationships between AAO and type of substance or sequencing were chosen on the basis of differences found in bivariate analyses and findings from earlier studies. They were identified as gender, type of BD (I versus II), a family history of affective/psychotic disorders, and excessive use of other substances than alcohol or cannabis. Possible mediators that did not show significant or trend level

Table 2 Sociodemographic and clinical characteristics in primary BD and secondary BD

\begin{tabular}{lccc}
\hline & $\begin{array}{l}\text { Primary BD } \\
N=117\end{array}$ & $\begin{array}{l}\text { Secondary BD } \\
N=34\end{array}$ & Statistics \\
\hline Age, y, mean (SD) & $36.50(12.2)$ & $33.7(10.4)$ & $t=1.2, d f=149, P=0.227^{\mathrm{a}}$ \\
AAO, y, mean (SD) & $21.8(9.0)$ & $25.9(9.8)$ & $t=-2.3, d f=149, \boldsymbol{P}=\mathbf{0 . 0 2 0}$ \\
Age at onset of excessive substance use, y, mean (SD)* & $27.0(11.6)$ & $20.1(7.0)$ & $t=2.9, d f=64, \boldsymbol{P}=\mathbf{0 . 0 0 5}^{\mathrm{a}}$ \\
Gender, female, $n(\%)$ & $74(63.2)$ & $18(52.9)$ & $\chi^{2}=1.2, d f=1, P=0.278^{\mathrm{b}}$ \\
Type I BD, (\%) & $68(58.1)$ & $23(67.6)$ & $\chi^{2}=1.0, d f=1, P=0.318^{\mathrm{b}}$ \\
Family history of affective/psychotic disorder, $n(\%)$ & $45(39)$ & $17(52)$ & $\chi^{2}=1.6, d f=1, P=0.204^{\mathrm{b}}$ \\
\hline
\end{tabular}

Significant $P$-values are typed in bold

$B D$ Bipolar disorder, $A A O$ Age at onset of BD, $y$ Years

* For the 32 patients with excessive substance use in the primary BD group

a Student's $t$-test

b Chi-square test 
Table 3 Sociodemographic and clinical characteristics of patients with excessive alcohol use, excessive cannabis use, or no excessive substance use

\begin{tabular}{|c|c|c|c|c|}
\hline & $\begin{array}{l}\text { No use, } \\
n=85 \text { (A) }\end{array}$ & $\begin{array}{l}\text { Alcohol use, } \\
n=28(\mathrm{~B})\end{array}$ & $\begin{array}{l}\text { Cannabis use, } \\
n=35 \text { (C) }\end{array}$ & Statistics \\
\hline Age, y, mean (SD) & $36.6(12.0)$ & $42.0(11.9)$ & $29.2(7.5)$ & $\begin{array}{l}F=10.9, d f=2,150, P<\mathbf{0 . 0 0 1}, \mathrm{A}, \mathrm{B}>\mathrm{C} \\
(\text { trend } \mathrm{A}<\mathrm{B} \text { ) }\end{array}$ \\
\hline $\mathrm{AAO}, \mathrm{y}$, mean $(\mathrm{SD})$ & $22.5(9.1)$ & $27.0(11.8)$ & $19.5(5.4)$ & $\begin{array}{l}F=5.5, d f=2,150, P=\mathbf{0 . 0 0 5}, \mathrm{B}>\mathrm{C} \\
\quad(\text { trend } \mathrm{A}<\mathrm{B} \text { ) }\end{array}$ \\
\hline $\begin{array}{l}\text { Age at onset of excessive substance use, } \\
y, \text { mean (SD) }\end{array}$ & N.A. & $30.9(11.3)$ & $17.0(2.7)$ & $t=6.0, d f=61, P<\mathbf{0 . 0 0 1}$ \\
\hline Gender, females (\%) & $59(69)$ & $13(46)$ & $19(54)$ & $\chi^{2}=5.7, d f=2, P=0.058($ trend $\mathrm{A}>\mathrm{B})$ \\
\hline Bipolar disorder, type I (\%) & $53(62)$ & $15(54)$ & $22(63)$ & $\chi^{2}=0.8, d f=2, P=0.683$ \\
\hline Family history, $n(\%)$ & $30(35)$ & $8(29)$ & $22(63)$ & $\chi^{2}=9.5, d f=2, \boldsymbol{P}=\mathbf{0 . 0 0 9}, \mathrm{A}, \mathrm{B}<\mathrm{C}$ \\
\hline Excessive use of other substances, $n(\%)$ & N.A. & $5(18)$ & $13(37)$ & $\chi^{2}=2.8, d f=1, P=0.092$ \\
\hline
\end{tabular}

$A A O$ age at onset of bipolar disorder, $y$ years, No use no excessive substance use, Alcohol use excessive use of alcohol

Cannabis use: excessive use of cannabis. Family history includes affective or psychotic disorders

effects were not entered in the final model. In the present material, age was highly correlated with AAO due to the focus on including mainly non-chronic patients in the study. Since preferred substance (alcohol or cannabis) may be a cohort phenomenon and influence AAO, age was still entered into the model. This model provided a better mathematical fit despite the colinearity. The variance accounted for by some of the other variables was, however, reduced. The analysis was performed hierarchically with several steps: first, gender and age; second, BD type and family history of affective/psychotic disorders; third, sequencing; and fourth, excessive alcohol and cannabis use. Reported are increase in $\mathrm{R}^{2}$ at each step, beta values, and their corresponding statistics from the final model.

\section{Results}

Patients with excessive alcohol use had a significantly later onset compared to patients with excessive cannabis use and showed a trend in the same direction relative to the nonusers (Table 3). Excessive alcohol users and non-users were older than the cannabis users. The excessive alcohol users also had a significantly later onset of the excessive substance use than the cannabis users. The proportion of patients with a family history of affective or psychotic disorders was significantly higher among the cannabis users compared with the alcohol users. There was a trend toward a greater proportion of females among the nonusers compared with the alcohol users. Follow-up analyses excluding patients using both alcohol and cannabis did not give any changes regarding group wise differences for age, $\mathrm{AAO}$ and age at onset of excessive substance use, or for the proportion with BD I or a family history of affective/ psychotic disorder. The difference in the proportion with excessive use of other substances was, however, no longer significant ( $18 \%$ vs. $25 \%, \chi^{2}=0.40, P=0.53$ ), implying that excessive polysubstance use was a characteristic of the excluded group.

AAO was earlier for primary BD compared with secondary $\mathrm{BD} \quad(21.8 \pm 9.0 \quad$ vs. $25.9 \pm 9.8, \quad P=0.02)$ (Table 2) and for cannabis users compared with alcohol users $(19.5 \pm 5.4$ vs. $27.9 \pm 11.8, P=0.005)$ (Table 3$)$ in both primary and secondary BD as illustrated in Fig. 1. There were no interaction effects between sequencing and type of substance use.

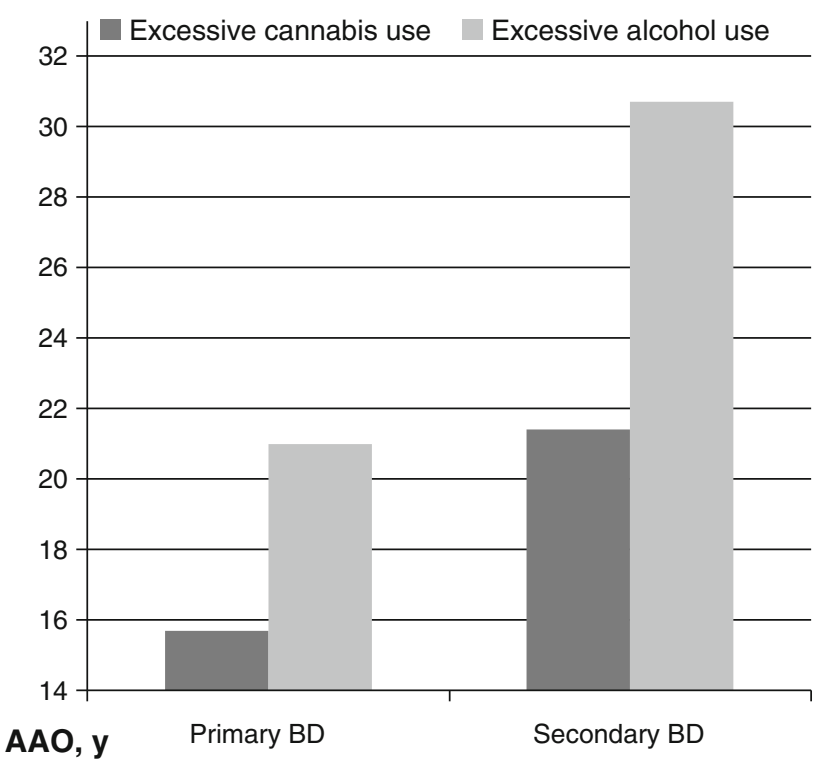

Fig. 1 The relationship between age at onset (AAO), sequencing and type of substance use. $y$ years 
Table 4 The correlations between AAO and sociodemographic and clinical variables

\begin{tabular}{lc}
\hline Variable & AAO \\
\hline Age & $0.52^{* *}$ \\
Gender & $-0.22^{* *}$ \\
BD type (I versus II) & $-0.19^{*}$ \\
Family history of affective/psychotic disorder & -0.15 \\
Age at onset of excessive substance use & $0.54^{* *}$ \\
Excessive cannabis use & $-0.19^{*}$ \\
Excessive alcohol use & 0.13 \\
Excessive use of other substances & -0.14 \\
Sequencing & $0.19^{*}$ \\
\hline
\end{tabular}

Data are expressed as Pearson correlations

$A A O$ Age at onset

$* p<0.05 ; * * p<0.01$

The bivariate analyses revealed significant correlations between AAO and gender, age, BD type, excessive cannabis use, and sequencing (Table 4).

The multiple regression analysis showed that sequencing and excessive cannabis use significantly predicted AAO after adjusting for gender, age, and BD type. Age and BD type also made significant contributions to the model, while gender contributed on a trend level (Table 5). Excessive use of alcohol was not a significant predictor nor was family history or excessive use of other substances. Lower age, BD II, primary BD, and excessive cannabis use independently predicted an earlier onset, with gender and age explaining $29 \%$ of the variance, type of $\mathrm{BD} 3 \%$, sequencing 5\% and alcohol and cannabis use another 5\%, with a total of $41 \%$ of the variance explained. Without age entered in the analysis, gender explained $5 \%$ of the variance, type of BD 3\%, sequencing $2.5 \%$ and alcohol and cannabis use another $13.5 \%$, with a total of $24 \%$ of the variance explained. Since sequencing was entered before cannabis use in the analyses, cannabis use appeared to predict an earlier onset regardless of whether it preceded or followed the onset of the BD.

\section{Discussion}

The main finding of the present study was that excessive cannabis use was associated with an earlier onset after adjusting for possible confounders, while excessive alcohol users had a later onset of the BD. Moreover, the mean age at onset of excessive cannabis use preceded the AAO of $\mathrm{BD}$, while the reverse was the case with alcohol.

We found clear differences between the alcohol users and the cannabis users. In addition to a later onset, the alcohol users were older, had a later onset of the excessive use, a lower prevalence of family history, and lower rates of use of other substances compared with the cannabis users. This has, to our knowledge, not been shown before. Our findings also suggest differences in sequencing between the alcohol and the cannabis users; for the alcohol users, the mean AAO was earlier than the mean age at onset of the excessive substance use, while for the cannabis users, the mean AAO was later than the mean age at onset of the excessive substance use. There was, however, no interaction effect between type of substance use and sequencing on AAO.

An earlier onset of excessive cannabis use compared with excessive alcohol use could be a societal phenomenon rather than related to $\mathrm{BD}$. Whether the age at onset of substance use disorders differs between substances has to our knowledge not been investigated in a general population sample. However, in a study of the age at first use of different substances, the age distribution curves were very similar for alcohol and cannabis, both peaking in late

Table 5 Multiple regression analysis of the effect of independent variables on age at onset

\begin{tabular}{|c|c|c|c|c|c|}
\hline Block no., variable & $R^{2}$ Change & Beta (SE) & 95\% Confidence Interval for B & $t$ & $P$ value \\
\hline Constant & & 17.33 & (10.30 to 24.36$)$ & 4.87 & $<0.001$ \\
\hline \multicolumn{6}{|l|}{1} \\
\hline Female & 0.29 & $-2.42(1.27)$ & $(-5.43$ to -0.17$)$ & -1.91 & 0.058 \\
\hline Age & & $0.36(0.06)$ & $(0.25$ to 0.46$)$ & 6.48 & $<0.001$ \\
\hline \multicolumn{6}{|l|}{2} \\
\hline BD I & 0.03 & $-2.73(1.23)$ & $(-5.16$ to -0.30$)$ & -2.22 & 0.028 \\
\hline \multicolumn{6}{|c|}{ 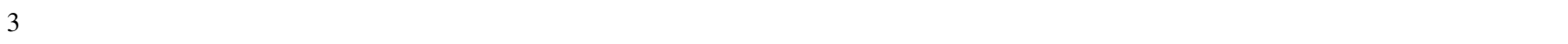 } \\
\hline Secondary BD & 0.05 & $8.20(1.79)$ & (4.67 to 11.72 ) & 4.59 & $<0.001$ \\
\hline \multicolumn{6}{|l|}{4} \\
\hline Excessive cannabis use & 0.05 & $-6.01(1.8)$ & $(-9.59$ to -2.43$)$ & -3.32 & 0.001 \\
\hline Excessive alcohol use & & $-0.33(1.43)$ & $(-3.16$ to 2.50$)$ & -0.23 & 0.817 \\
\hline
\end{tabular}

Final model, $R^{2}=0.41, F=16.65, P<0.001$ 
adolescence [43]. The later onset in alcohol users compared with cannabis users may thus indicate that different mechanisms are involved in the relationships between the development of BD and these two most frequently used substances. However, due to the present study's crosssectional and naturalistic design, the findings are primarily hypothesis generating. Taken together, our findings may indicate that cannabis to a greater extent than alcohol influences the onset of BD. This is in line with two recent studies on acutely ill patients with a broad spectrum of psychotic disorders, showing that cannabis abuse/dependence was associated with an earlier onset of the psychotic disorders after adjusting for abuse/dependence of other substances including alcohol [44, 45]. Our findings indicate that the association between AAO and excessive cannabis use is present also in a pure BD sample. This is in line with the growing evidence that cannabis use is a risk factor for developing manic symptoms and BD [37-39], while alcohol abuse seems to increase the risk for depressive rather than manic symptomatology [36, 46]. Furthermore, in a recent study on prodromes of first manic psychotic episode, $68 \%$ of patients were found to have substance use disorders in the prodromal phase, of which $82 \%$ used cannabis [47]. Also, it is fairly well established that cannabis use composes a risk factor for the development of psychosis/ schizophrenia [48]. Cell toxicity or disruption of neurotransmitter coordination caused by long-term heavy cannabis use has been suggested as a possible mechanism behind this increased risk [49]. The fact that schizophrenia and $\mathrm{BD}$ have many clinical features in common as well as overlapping pathophysiology [50] increases the plausibility that cannabis use may act as a risk factor also in BD.

The association between cannabis use and early onset in the current study was present also after adjusting for sequencing and appears to exist also when the excessive use develops after the BD. This indicates that an early onset increases the risk of subsequently developing excessive cannabis use. This is in accordance with earlier findings of an association between early BD onset and drug abuse $[19,51]$, which may have several explanations. Some authors have proposed that patients with early onset may share a common increased genetic vulnerability mediating both BD and excessive drug use [13]. Family history did not independently predict AAO in the present study. However, the family history rates of affective/psychotic disorders among the cannabis users were high. Having a close family member with a severe psychiatric disorder in addition to experiencing affective episodes early in life may also represent a substantial psychosocial burden, leaving the patient at increased risk for illicit substance use.

The present finding that cannabis use predicts an earlier onset regardless of sequencing is in contrast to earlier findings of a later onset of BD secondary to cannabis [29].
This discrepancy could be due to differences in methodology and sample characteristics. One explanation may be the high family history rates in our sample of excessive cannabis users, on which no data were presented in the previous study. Higher family history rates may indicate high vulnerability for $\mathrm{BD}$, which may interact with excessive cannabis use to cause an early onset in these patients. The complex relationship between AAO, type of substance used, sequencing and family history should be further explored in a greater sample allowing comparisons on several subgroup levels.

One possible explanation for the association between early onset of BD and excessive cannabis use could be a cohort effect, i.e. that people born in the last decades may be at greater risk for developing excessive cannabis use than patients born earlier due to trends in substance use or increased availability. However, since excessive cannabis use still predicted AAO after adjusting for age, this cannot explain the finding. The association between earlier onsets and cannabis use was also present after adjusting for family history and excessive use of other substances. Thus, it is unlikely the present findings can be explained in terms of these potential confounders.

The present finding that secondary BD predicted a later onset (relative to primary BD) is highly consistent with earlier studies [26-31, 52]. We also demonstrate that this effect remains significant even after adjusting for several variables known to be associated with AAO (gender, BD type, family history, type of substance used), further supporting the hypothesis that the excessive substance use may trigger BD. We do not replicate earlier findings that family history is associated with AAO [8], or that family history rates are lower in secondary $\mathrm{BD}$ compared with primary BD [27]. We do, however, demonstrate that the family history rates are higher among the cannabis users compared with the alcohol users and the non-users. Patients' reports of family history of psychiatric disorders are a somewhat crude measure [53], which may explain these inconsistencies. Furthermore, the full range of vulnerability markers and risk factors for BD are not yet known, thus other factors may have confounded the results.

In the multivariate analyses, we found that BD II disorder independently predicted an earlier onset, with the same trend for female gender. Recent studies on the association between $\mathrm{AAO}$, gender, and $\mathrm{BD}$ type are somewhat diverging; one study reported earlier onsets in females but no differences regarding BD type [12], while another reported that males and BD I had an earlier onset compared with females and BD II [3]. The latter finding is in contrast to the present study, while the former showed similar results. This suggests that gender and BD type are relevant when investigating $\mathrm{AAO}$, but future studies are needed to clarify these questions. Also, the findings of the 
present study suggest that the prevalence of excessive cannabis use could account for differences between populations in AAO.

The present study has some limitations. Data on substance use and illness characteristics including AAO were gathered retrospectively, risking recall bias. There is, however, no reason to believe that this should affect the subgroups differently. Furthermore, some of the subgroups in the bivariate analyses are small, increasing the risk of type II errors. Lastly, a control population in which the age at onset of excessive cannabis versus alcohol use was investigated would have provided data indicating whether these differences are societal phenomena or related to the BD.

\section{Conclusion}

Excessive cannabis use is associated with an early onset regardless of whether it precedes or follows the $\mathrm{BD}$, while excessive use of alcohol or other substances is not independently associated with AAO. General excessive substance use prior to $\mathrm{BD}$ onset is associated with a later onset. The relationship between cannabis use and BD onset should be further investigated in prospective studies.

Open Access This article is distributed under the terms of the Creative Commons Attribution Noncommercial License which permits any noncommercial use, distribution, and reproduction in any medium, provided the original author(s) and source are credited.

\section{References}

1. Goodwin FK, Ghaemi SN, Jamison KR (2007) Manic-depressive illness: bipolar disorders and recurrent depression. Oxford University Press, Oxford

2. Post RM, Luckenbaugh DA, Leverich GS, Altshuler LL, Frye MA, Suppes T, Keck PE, McElroy SL, Nolen WA, Kupka R, Grunze H, Walden J (2008) Incidence of childhood-onset bipolar illness in the USA and Europe. Br J Psychiatry 192:150-151

3. Baldessarini RJ, Bolzani L, Cruz N, Jones PB, Lai M, Lepri B, Perez J, Salvatore P, Tohen M, Tondo L, Vieta E (2010) Onsetage of bipolar disorders at six international sites. J Affect Disord 121:143-146

4. Larsson S, Lorentzen S, Mork E, Barrett EA, Steen NE, Lagerberg TV, Berg AO, Aminoff SR, Agartz I, Melle I, Andreassen OA (2010) Age at onset of bipolar disorder in a Norwegian catchment area sample. J Affect Disord 124:174-177

5. Morken G, Vaaler AE, Folden GE, Andreassen OA, Malt UF (2009) Age at onset of first episode and time to treatment in inpatients with bipolar disorder. Br J Psychiatry 194:559-560

6. Oedegaard KJ, Syrstad VE, Morken G, Akiskal HS, Fasmer OB (2009) A study of age at onset and affective temperaments in a Norwegian sample of patients with mood disorders. J Affect Disord 118:229-233

7. Larsson S, Lorentzen S, Mork E, Barrett EA, Steen NE, Lagerberg TV, Berg AO, Aminoff SR, Agartz I, Melle I, Andreassen OA (2009) Age at onset of bipolar disorder in a Norwegian catchment area sample. J Affect Disord (In press)
8. Leboyer M, Henry C, Paillere-Martinot ML, Bellivier F (2005) Age at onset in bipolar affective disorders: a review. Bipolar Disord 7:111-118

9. Strober M (1992) Relevance of early age-of-onset in genetic studies of bipolar affective disorder. J Am Acad Child Adolesc Psychiatry 31:606-610

10. Johnson L, Andersson-Lundman G, Ảberg-Wistedt A, Mathe AA (2000) Age of onset in affective disorder: its correlation with hereditary and psychosocial factors. J Affect Disord 59:139-148

11. Hendrick V, Altshuler LL, Gitlin MJ, Delrahim S, Hammen C (2000) Gender and bipolar illness. J Clin Psychiatry 61:393-396

12. Suominen K, Mantere O, Valtonen H, Arvilommi P, Leppamaki S, Isometsa E (2009) Gender differences in bipolar disorder type I and II. Acta Psychiatr Scand 120:464-473

13. Lin PI, McInnis MG, Potash JB, Willour V, MacKinnon DF, DePaulo JR, Zandi PP (2006) Clinical correlates and familial aggregation of age at onset in bipolar disorder. Am J Psychiatry 163:240-246

14. Judd LL, Akiskal HS, Schettler PJ, Coryell W, Maser J, Rice JA, Solomon DA, Keller MB (2003) The comparative clinical phenotype and long term longitudinal episode course of bipolar I and II: a clinical spectrum or distinct disorders? J Affect Disord 73:19-32

15. Garno JL, Goldberg JF, Ramirez PM, Ritzler BA (2005) Impact of childhood abuse on the clinical course of bipolar disorder. Br J Psychiatry 186:121-125

16. Leverich GS, McElroy SL, Suppes T, Keck PE Jr, Denicoff KD, Nolen WA, Altshuler LL, Rush AJ, Kupka R, Frye MA, Autio KA, Post RM (2002) Early physical and sexual abuse associated with an adverse course of bipolar illness. Biol Psychiatry 51:288-297

17. Carlson GA, Bromet EJ, Sievers S (2000) Phenomenology and outcome of subjects with early- and adult-onset psychotic mania. Am J Psychiatry 157:213-219

18. Ernst CL, Goldberg JF (2004) Clinical features related to age at onset in bipolar disorder. J Affect Disord 82:21-27

19. Perlis RH, Miyahara S, Marangell LB, Wisniewski SR, Ostacher M, DelBello MP, Bowden CL, Sachs GS, Nierenberg AA (2004) Long-Term implications of early onset in bipolar disorder: data from the first 1,000 participants in the systematic treatment enhancement program for bipolar disorder (STEP-BD). Biol Psychiatry 55:875-881

20. Carter TD, Mundo E, Parikh SV, Kennedy JL (2003) Early age at onset as a risk factor for poor outcome of bipolar disorder. J Psychiatr Res 37:297-303

21. Goldstein BI, Levitt AJ (2006) Further evidence for a developmental subtype of bipolar disorder defined by age at onset: results from the national epidemiologic survey on alcohol and related conditions. Am J Psychiatry 163:1633-1636

22. Cassidy F, Ahearn EP, Carroll BJ (2001) Substance abuse in bipolar disorder. Bipolar Disord 3:181-188

23. Goldberg JF, Garno JL, Leon AC, Kocsis JH, Portera L (1999) A history of substance abuse complicates remission from acute mania in bipolar disorder. J Clin Psychiatry 60:733-740

24. McElroy SL, Altshuler LL, Suppes T, Keck PE Jr, Frye MA, Denicoff KD, Nolen WA, Kupka RW, Leverich GS, Rochussen JR, Rush AJ, Post RM (2001) Axis I psychiatric comorbidity and its relationship to historical illness variables in 288 patients with bipolar disorder. Am J Psychiatry 158:420-426

25. Ringen PA, Lagerberg TV, Birkenaes AB, Engn J, Faerden A, Jonsdottir H, Nesvag R, Friis S, Opjordsmoen S, Larsen F, Melle I, Andreassen OA (2008) Differences in prevalence and patterns of substance use in schizophrenia and bipolar disorder. Psychol Med 38:1241-1249

26. Feinman JA, Dunner DL (1996) The effect of alcohol and substance abuse on the course of bipolar affective disorder. J Affect Disord 37:43-49 
27. DelBello MP, Strakowski SM, Sax KW, McElroy SL, Keck PE Jr, West SA, Kmetz GF (1999) Familial rates of affective and substance use disorders in patients with first-episode mania. J Affect Disord 56:55-60

28. Strakowski SM, DelBello MP, Fleck DE, Adler CM, Anthenelli RM, Keck PE Jr, Arnold LM, Amicone J (2005) Effects of cooccurring alcohol abuse on the course of bipolar disorder following a first hospitalization for mania. Arch Gen Psychiatry $62: 851-858$

29. Strakowski SM, DelBello MP, Fleck DE, Adler CM, Anthenelli RM, Keck PEJ, Arnold LM, Amicone J (2007) Effects of cooccurring cannabis use disorders on the course of bipolar disorder after a first hospitalization for mania. Arch Gen Psychiatry 64:57-64

30. Fossey MD, Otto MW, Yates WR, Wisniewski SR, Gyulai L, Allen MH, Miklowitz DJ, Coon KA, Ostacher MJ, Neel JL, Thase ME, Sachs GS, Weiss RD, Investigators FS (2006) Validity of the distinction between primary and secondary substance use disorder in patients with bipolar disorder: data from the first 1,000 STEP-BD participants. Am J Addict 15:138-143

31. Strakowski SM, McElroy SL, Keck PE Jr, West SA (1996) The effects of antecedent substance abuse on the development of firstepisode psychotic mania. J Psychiatr Res 30:59-68

32. Winokur G, Coryell W, Akiskal HS, Maser JD, Keller MB, Endicott J, Mueller T (1995) Alcoholism in manic-depressive (bipolar) illness: familial illness, course of illness, and the primary-secondary distinction. Am J Psychiatry 152:365-372

33. Goldstein BI, Levitt AJ (2006) Factors associated with temporal priority in comorbid bipolar I disorder and alcohol use disorders: results from the national epidemiologic survey on alcohol and related conditions. J Clin Psychiatry 67:643-649

34. Pacchiarotti I, Marzo SD, Colom F, Sanchez-Moreno J, Vieta E (2007) Bipolar disorder preceded by substance abuse: a different phenotype with not so poor outcome? World J Biol Psychiatry $1-8$

35. Strakowski SM, DelBello MP, Fleck DE, Arndt S (2000) The impact of substance abuse on the course of bipolar disorder. Biol Psychiatry 48:477-485

36. Baethge C, Hennen J, Khalsa HM, Salvatore P, Tohen M, Baldessarini RJ (2008) Sequencing of substance use and affective morbidity in 166 first-episode bipolar I disorder patients. Bipolar Disord 10:738-741

37. Henquet C, Krabbendam L, de Graaf R, ten Have M, van Os J (2006) Cannabis use and expression of mania in the general population. J Affect Disord 95:103-110

38. Tijssen MJ, van OJ, Wittchen HU, Lieb R, Beesdo K, Wichers M (2010) Risk factors predicting onset and persistence of subthreshold expression of bipolar psychopathology among youth from the community. Acta Psychiatr Scand

39. van Laar M, van Dorsselaer S, Monshouwer K, de Graaf R (2007) Does cannabis use predict the first incidence of mood and anxiety disorders in the adult population? Addiction 102:1251-1260

40. Lichtenstein P, Yip BH, Bjork C, Pawitan Y, Cannon TD, Sullivan PF, Hultman CM (2009) Common genetic determinants of schizophrenia and bipolar disorder in Swedish families: a population-based study. Lancet 373:234-239

41. Craddock N, O'Donovan MC, Owen MJ (2009) Psychosis genetics: modeling the relationship between schizophrenia, bipolar disorder, and mixed (or "schizoaffective") psychoses. Schizophr Bull 35:482-490

42. Lagerberg TV, Andreassen OA, Ringen PA, Berg AO, Larsson S, Agartz I, Sundet K, Melle I (2010) Excessive substance use in bipolar disorder is associated with impaired functioning rather than clinical characteristics, a descriptive study. BMC Psychiatry 10:9

43. Vega WA, Aguilar-Gaxiola S, Andrade L, Bijl R, Borges G, Caraveo-Anduaga JJ, DeWit DJ, Heeringa SG, Kessler RC, Kolody B, Merikangas KR, Molnar BE, Walters EE, Warner LA, Wittchen HU (2002) Prevalence and age of onset for drug use in seven international sites: results from the international consortium of psychiatric epidemiology. Drug Alcohol Depend 68:285-297

44. Öngür D, Lin L, Cohen BM (2009) Clinical characteristics influencing age at onset in psychotic disorders. Compr Psychiatry 50:13-19

45. Gonzalez-Pinto A, Vega P, Ibanez B, Mosquera F, Barbeito S, Gutierrez M, de Ruiz AS, Ruiz I, Vieta E (2008) Impact of cannabis and other drugs on age at onset of psychosis. J Clin Psychiatry 69:1210-1216

46. Fergusson DM, Boden JM, Horwood LJ (2009) Tests of causal links between alcohol abuse or dependence and major depression. Arch Gen Psychiatry 66:260-266

47. Conus P, Ward J, Lucas N, Cotton S, Yung AR, Berk M, McGorry PD (2010) Characterisation of the prodrome to a first episode of psychotic mania: Results of a retrospective study. J Affect Disord (In press)

48. D'Souza DC, Sewell RA, Ranganathan M (2009) Cannabis and psychosis/schizophrenia: human studies. Eur Arch Psychiatry Clin Neurosci 259:413-431

49. Roser P, Della B, Norra C, Uhl I, Brune M, Juckel G (2010) Auditory mismatch negativity deficits in long-term heavy cannabis users. Eur Arch Psychiatry Clin Neurosci 260:491-498

50. Murray RM, Sham P, van Os J, Zanelli J, Cannon M, McDonald C (2004) A developmental model for similarities and dissimilarities between schizophrenia and bipolar disorder. Schizophr Res 71:405-416

51. Wilens TE, Biederman J, Millstein RB, Wozniak J, Hahesy AL, Spencer TJ (1999) Risk for substance use disorders in youths with child- and adolescent-onset bipolar disorder. J Am Acad Child Adolesc Psychiatry 38:680-685

52. Falk DE, Yi HY, Hilton ME (2008) Age of onset and temporal sequencing of lifetime DSM-IV alcohol use disorders relative to comorbid mood and anxiety disorders. Drug Alcohol Depend 94:234-245

53. Roy MA, Walsh D, Kendler KS (1996) Accuracies and inaccuracies of the family history method: a multivariate approach. Acta Psychiatr Scand 93:224-234 